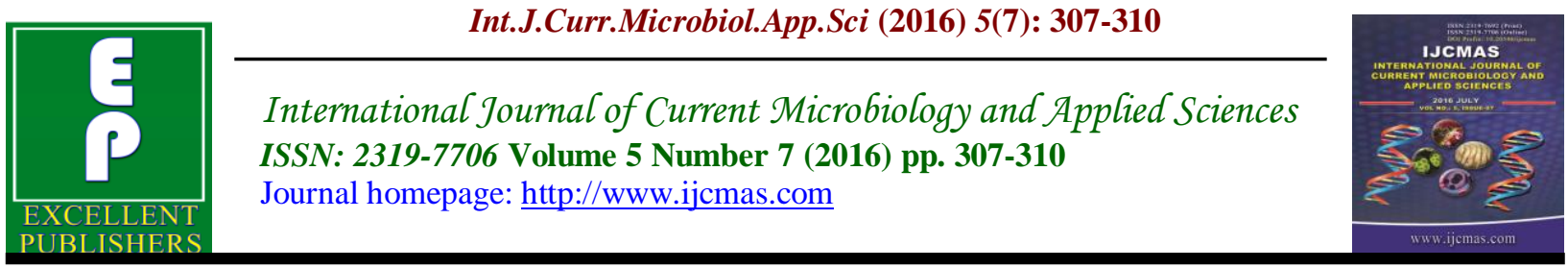

Case Study

http://dx.doi.org/10.20546/ijcmas.2016.507.032

\title{
Mycetoma Foot caused by Fusarium solani in a Young Boy from Karnataka, India
}

\author{
B. Sumangala ${ }^{1}$, N.S. Sahana Shetty ${ }^{1}$, B. Kala ${ }^{2}$ and M. Kavya ${ }^{3}$ \\ ${ }^{1}$ Department of Microbiology, MIMS, Mandya, India \\ ${ }^{2}$ Department of Pathology, MIMS, Mandya, India \\ ${ }^{3}$ Department of Dermatology, MIMS, Mandya, India \\ *Corresponding author
}

\begin{tabular}{|c|c|}
\hline & A B S T R A C T \\
\hline $\begin{array}{l}\text { K e y w o r d s } \\
\text { Mycetoma, } \\
\text { Fusariom solani, } \\
\text { onychomycosis. }\end{array}$ & \multirow{3}{*}{$\begin{array}{l}\text { Fusarium species are common soil-inhabiting organisms and plant } \\
\text { pathogens. Human infections are usually precipitated by local or systemic } \\
\text { predisposing factors, and disseminated infection is associated with impaired } \\
\text { immune responses. Skin infections caused by Fusarium spp include } \\
\text { keratitis, onychomycosis, mycetoma, painful discrete erythematous nodules. } \\
\text { We report a case of mycetoma caused by Fusariom solani in an } \\
\text { immunocompetent young boy from Karnataka. }\end{array}$} \\
\hline Article Info & \\
\hline $\begin{array}{l}\text { Accepted: } \\
\text { 12 June } 2016 \\
\text { Available Online: } \\
\text { 10 July } 2016\end{array}$ & \\
\hline
\end{tabular}

\section{Introduction}

Mycetomas are chronic subcutaneous infections caused by fungi or actinomycetes, known as eumycetoma and actinomycetoma, respectively (Hay, 2005). It is usually posttraumatic, most commonly involves foot and rarely other body parts. It is mainly seen in Africa, India, Mexico, and South America. In India, actinomycetoma is prevalent in South, Southeast Rajasthan, and Chandigarh; while eumycetomas are common in North India (Chakraborti et al., 1998). The most common agents of eumycetomas are Madurella mycetomatis, Madurellagrisea, Acremonium spp. and Fusarium spp (Kaur et al., 2013).

Fusarium species are common soilinhabiting organisms and plant pathogens.
Among immunocompetent patients, tissue breakdown (trauma, severe burns or foreign body) is the risk factor for fusariosis. Superficial infections commonly caused by Fusarium spp.

Include keratitis, onychomycosis, and Mycetoma while cellulitis, erythematous pustules, painful discrete erythematous nodules, and ulcerative lesions are less common.

\section{Case Report}

A 20 year old boy belonging to low socioeconomic status presented with mildly painful swelling of 4years duration on the sole of left foot. There was history of thorn 
prick. On examination, the patient was apparently healthy. There was no other significant finding. Local examination showed ulcer over the sole of the left foot (Fig 1). Examination revealed non healing ulcer measuring $4 \times 3 \times 3 \mathrm{~cm}$ with verrucous changes of skin at the periphery. Skin biopsy was taken from the lesion. A saline mount, $\mathrm{KOH}$ mount, Gram's-stain smear, and modified acid fast stain decolorized with $1 \%$ sulphuric acid and $\mathrm{H}$ and E, PAS (Fig 4), GMS stained smears were examined (Fig 5).

Direct $\mathrm{KOH}$ mount of the lesion showed septate branching hyaline hyphae(Fig 2). Culture done on Sabourauds Dextrose Agar (SDA) with and without cycloheximide revealed whitish-grey cottony colonies after 2 days of incubation at $37^{\circ} \mathrm{C}$ (Fig 3). No growth was observed on Sabourauds Dextrose Agar (SDA) with cycloheximide agar. Lactophenol cottonblue mount from the colonies showed branched septate hyphae with small oval-shaped macroconidia and single-celled microconidia, suggestive of Fusarium spp. On histopathology, hyperkeratosis with fungal hyphae was detected. Modified acid fast staining did not show any acid-fast bacilli. X-ray foot of the patient did not reveal any bony invasion.

\section{Results and Discussion}

F. solani is widely distributed plant pathogen. Fusarium species have been reported from variety of clinical conditions like keratitis, skin infection in burns, variety of skin lesions, arthritis, peritonitis, systemic infection in immunocompromised hosts, systemic, and granulomatous diseases, in a plastic anemia. Recently, a case of breast abscess in diabetic patient has been reported.

Fig.1

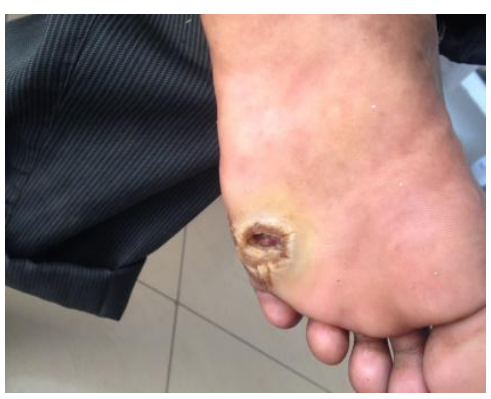

Fig.2

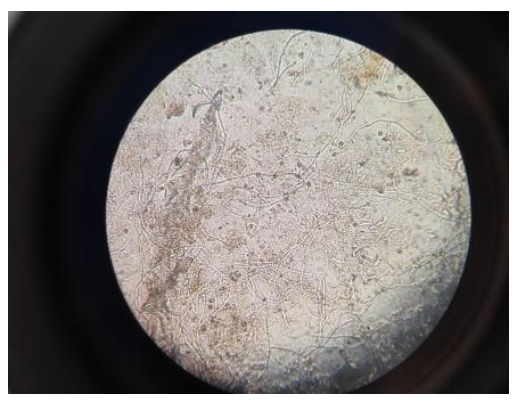


Fig.3

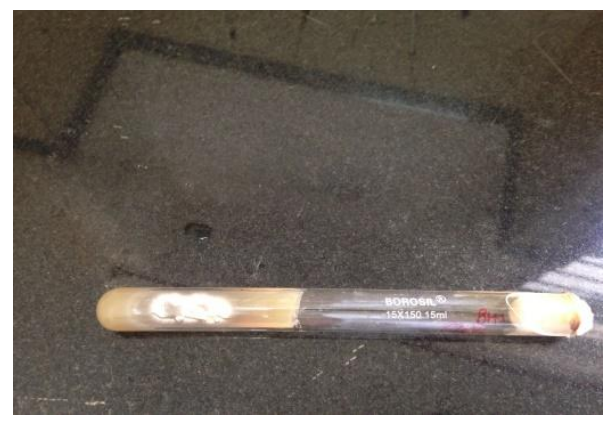

Fig.4

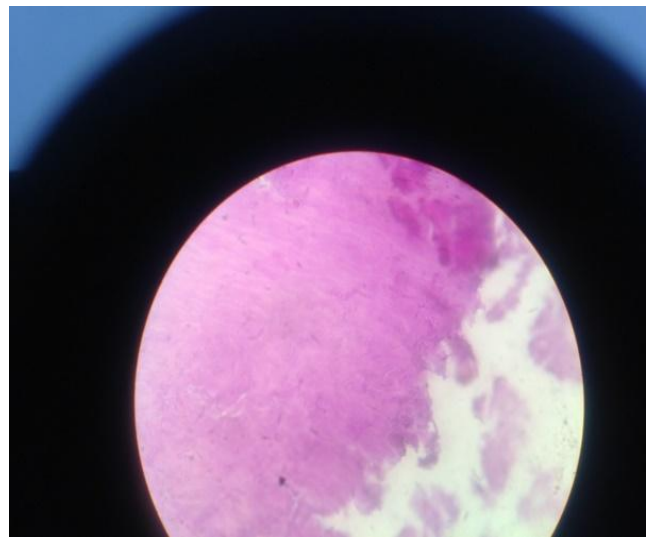

Fig.5

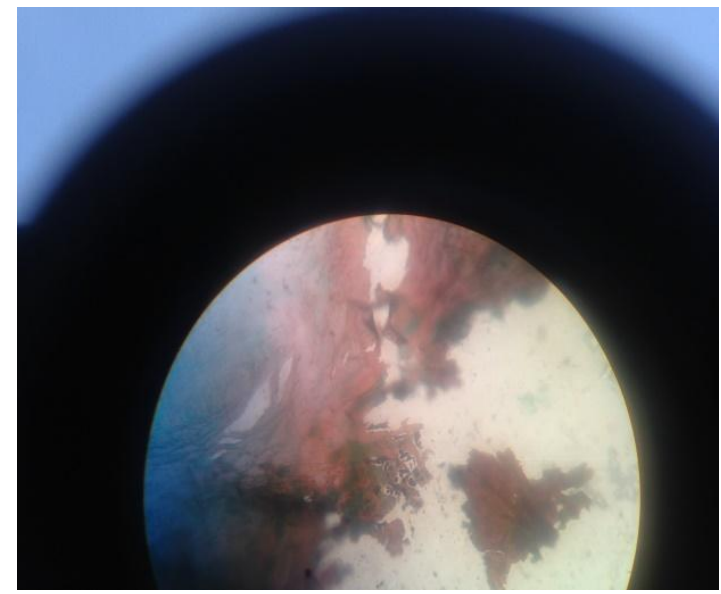

The earliest documented Fusarium mycetoma report is from Senegal. Thepatient may have acquired the fungus following trauma and showed slow progression of the lesion as reported in immunocompetent patients. The diagnosis of Fusarium infection may be made on histopathology, fungal culture. Tissue invasion can be studied by histopathological examination

In conclusion, it is very important to 
determine the causative agent in every patient suspected of Mycetoma to establish an adequate and timely plan for appropriate management to avoid persistence, dissemination of the disease and recurrence.

\section{Acknowledgement}

We thank Dr. Shivaprakash, Sunita Gupta, NCCPF(Mycology division), Centre of Advance Research in Medical Mycology \& WHO Collaborating Centre Department of Medical Microbiology, Postgraduate institute of Medical Education \& Research, Chandigarh.

\section{References}

Bassiri-Jahromi. S. 2014. Mycetoma in Iran: Causative agents and geographic distribution. Indian J. Dermatol., 59: 529.

Chakraborti, A., Singh, K. 1998. Mycetoma in Chandigarh and surrounding areas. Indian J. Med. Microbiol., 16: 64- 5.

Hay, R.J. 2005. Agents of eumycotic Mycetomas. Topley and Wilsons Textbook of Microbiology. 10th ed., Vol. 4. London: Hodder Arnold Ltd.; 2005. p. 487-96.
Katkar, V.J., Tankhiwale, S.S., Kurhade, A. 2011. Fusarium soloni mycetoma. Indian J. Dermatol., 56: 315-7.

Kaur, R., Maheshwari, M. 2013. Hyperkeratotic Warty Skin Lesion of Foot Caused by Fusarium oxysporum. Indian J. Dermatol., 58: 159.

Kudur, M.H., Prakash, P.Y., Savitha, M. 2013. FusariumSolani Causing Quasi- Invasive Infection of the Foot in an Immunocompetent Middle- Aged Man from South India. Indian J. Dermatol., 58: 241.

Nucci, M., Anaissie, E. 2007. Fusarium Infections in Immunocompromised Patients. Clin. Microbiol. Rev., 20: 695-704.

Rippon, J.W. 1988. Medical Mycology. 3rd ed. Philadelphia: W.B. Saunders Co.

Shinde, R.S., Hanumantha, S., Mantur, B.G., Parande, M.V. 2015. A rare case of mycetoma due to Curvularia. J. Lab. Physicians, 7: 55-7.

Yera, H., Bougnoux, M.E., Jeanrot, C., Baixench, M.T., De Pinieux, G., Dupouy-Camet, J. 2003. Mycetoma of the Foot Caused by Fusarium solani: Identification of the Etiologic Agent by DNA Sequencing, J. Clin. Microbiol., 41: 1805-8.

\section{How to cite this article:}

Sumangala, B., N.S. Sahana Shetty, B. Kala and Kavya, M. 2016. Mycetoma Foot caused by Fusarium solani in a Young Boy from Karnataka, India. Int.J.Curr.Microbiol.App.Sci. 5(7): 307-310. doi: http://dx.doi.org/10.20546/ijcmas.2016.507.032 